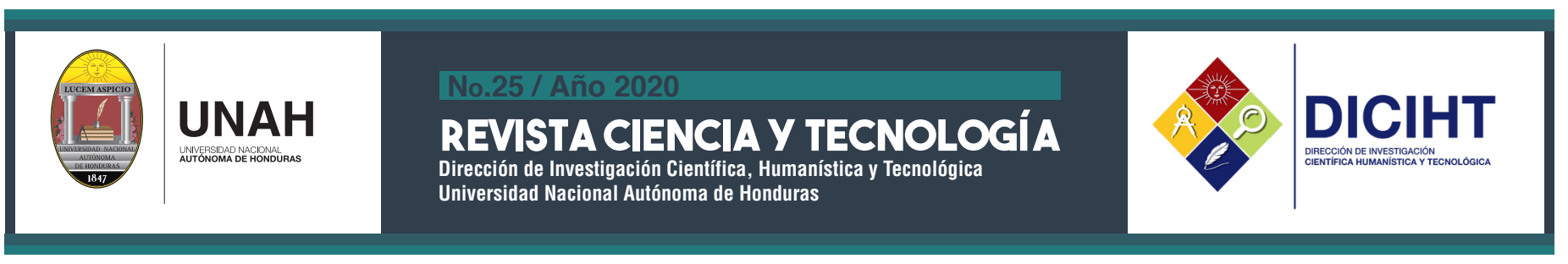

\title{
REVISIÓN BIBLIOCRÁFICA
}

\section{Terapias farmacológicas utilizadas en el tratamiento de la COVID-19. Revisión bibliográfica}

\section{Pharmacological therapies used in COVID-19 treatment. Bibliographic review}

Lilian Sosa ${ }^{\mathrm{a}}$, Henry Ponce ${ }^{\mathrm{b}}$, Fredy Rodríguez $^{\mathrm{b}}$, Karen Orellana $^{\mathrm{b}}$, Dennis Cerrato $^{\mathrm{c}}$

a Dirección de Investigación Científica, Humanística y Tecnológica, DICIHT. Universidad Nacional Autónoma de Honduras (UNAH), Tegucigalpa, Honduras

b Facultad de Ciencias Químicas y Farmacia, Universidad Nacional Autónoma de Honduras (UNAH), Tegucigalpa, Honduras

c Centro de Investigación y de Estudios Avanzados del Instituto Politécnico Nacional, CINVESTAV, México D.F., México

\section{RESUMEN}

A finales del año 2019, surgió en China un brote de una enfermedad causada por un nuevo coronavirus conocido internacionalmente como COVID-19, propagándose por todo el mundo y declarada como pandemia en marzo del año 2020. Este virus ocasiona enfermedades respiratorias que van desde síntomas muy leves hasta cuadros severos, pudiendo ocasionar la muerte del paciente. No obstante, el marcado aumento en la comprensión del virus y la enfermedad ha permitido el desarrollo de pruebas diagnósticas, actuales ensayos in-vitro y ensayos clínicos de fármacos, así como vacunas y medidas de control epidemiológico. En el presente artículo, realizamos una revisión de la información disponible en bases de datos como: Pubmed, MedlinePlus, EMBASE o Scopus, Cochrane Library, LILACS, índice Médico Español (IME), entre otras, hasta junio del presente año, para conocer más acerca del patógeno, transmisión, síntomas, diagnóstico, patogénesis y centrándonos en los tratamientos farmacológicos mayoritariamente estudiados a nivel mundial.
Palabras clave: SARS-CoV, MERS-CoV, SARSCoV-2, COVID-19, tratamiento farmacológico, ensayos clínicos

\section{ABSTRACT}

In late 2019, an outbreak of a disease caused by a new coronavirus known internationally as COVID-19 emerged in China, spreading worldwide and declared a pandemic in March 2020. This virus causes respiratory diseases ranging from very slight to severe symptoms, which may cause the death of the patient. However, the marked increase in the understanding of the virus and the disease has allowed the development of diagnostic tests, current in-vitro trials and clinical trials of drugs, vaccines, and epidemiological control measures. In this article, we carry out a review of the information available in databases such as: Pubmed, MedlinePlus, EMBASE or Scopus, Cochrane Library, LILACS, Spanish Medical Index (IME), among others, until June of this year, to learn more about the pathogen, transmission, symptoms, diagnosis,

\footnotetext{
Autor corresponsal

$\triangle$ Lilian Sosa

liliansosa2012@gmail.com
} 
pathogenesis and focusing on the pharmacological treatments mainly studied worldwide.

Key words: SARS-CoV, MERS-CoV, SARS-CoV-2, COVID-19, pharmacological treatments, clinical trials

\section{INTRODUCCIÓN}

Los coronavirus son un grupo de virus que pertenecen a la familia coronaviridae, con tamaño diminuto (65-125 nm de diámetro), conteniendo un ARN monocatenario como material nucleico (Fig. 1) y dividiéndose en subgrupos: alfa $(\alpha)$, beta $(\beta)$, gamma $(\gamma)$ y delta $(\delta)$, siendo los dos primeros los causantes de los coronavirus humanos (Zhong et al. 2003). Asimismo, estos son promotores de enfermedades respiratorias que van desde un resfriado común hasta enfermedades más graves, como son los casos de los coronavirus causantes del síndrome respiratorio de Oriente Medio (MERS-CoV, Middle East Respiratory Syndrome, por sus siglas en inglés) y el que ocasiona el síndrome respiratorio agudo severo (SARS-CoV, Severe Acute Respiratory Syndrome, por sus siglas en inglés) (OMS 2020a).

A finales del año 2019, Wuhan, un centro de negocios emergente de China, experimentó un brote de un nuevo coronavirus que infectó a más de setenta mil individuos dentro de los primeros cincuenta días de la epidemia. El virus provocó la infección respiratoria aguda causada por el coronavirus 2 del síndrome respiratorio agudo severo (SARS-CoV-2, Severe Acute Respiratory Syndrome 2, por sus siglas en inglés), causante de la enfermedad del coronavirus 2019 (COVID-19, Coronavirus disease 2019, por sus siglas en inglés). Se extendió por todo el mundo, declarándose como pandemia el 11 de marzo del 2020 (Shereen et al. 2020; Ghinai et al. 2020; Lai et al. 2020).

Hasta la fecha, conocemos que el SARS-CoV-2 ha logrado expandirse en la mayor parte de los países del mundo y debido a los movimientos migratorios, este virus fue propagándose, dejando cientos de personas infectadas. Cada día, las estadísticas cambian, por lo que solamente podemos mencionar que se han reportado más de 20 millones de infectados, incluidos más de medio millón de fallecidos (CIDBIMENA y Relaciger 2020).

\section{TRANSMISIÓN, SÍNTOMAS Y DIAGNÓSTICO}

\subsection{Transmisión}

Las características epidemiológicas, como la fuente de origen y forma de transmisión del virus, son determinantes para desarrollar estrategias preventivas contra la infección(Shereen etal. 2020). Se sospecha que

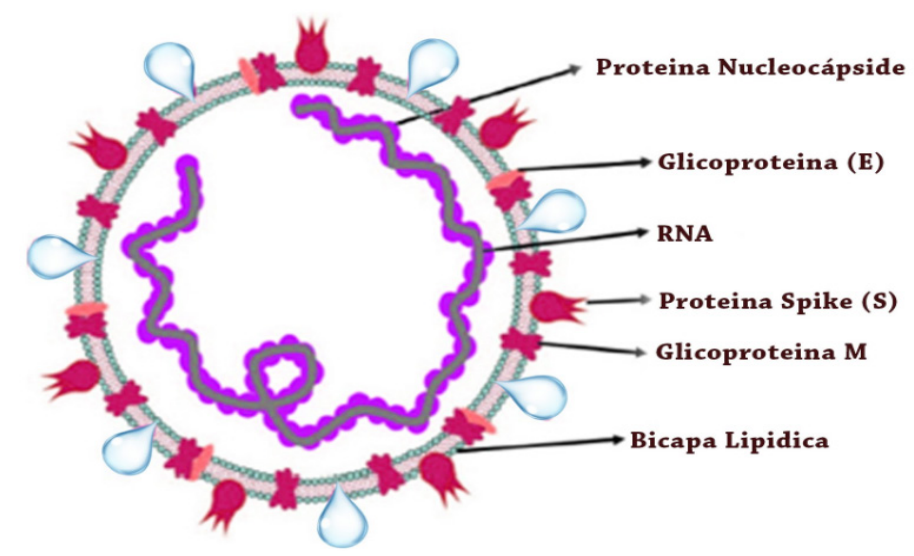

Fig. 1 Estructura del virus causante del coronavirus humano (adaptado de Shereen et al. 2020) 


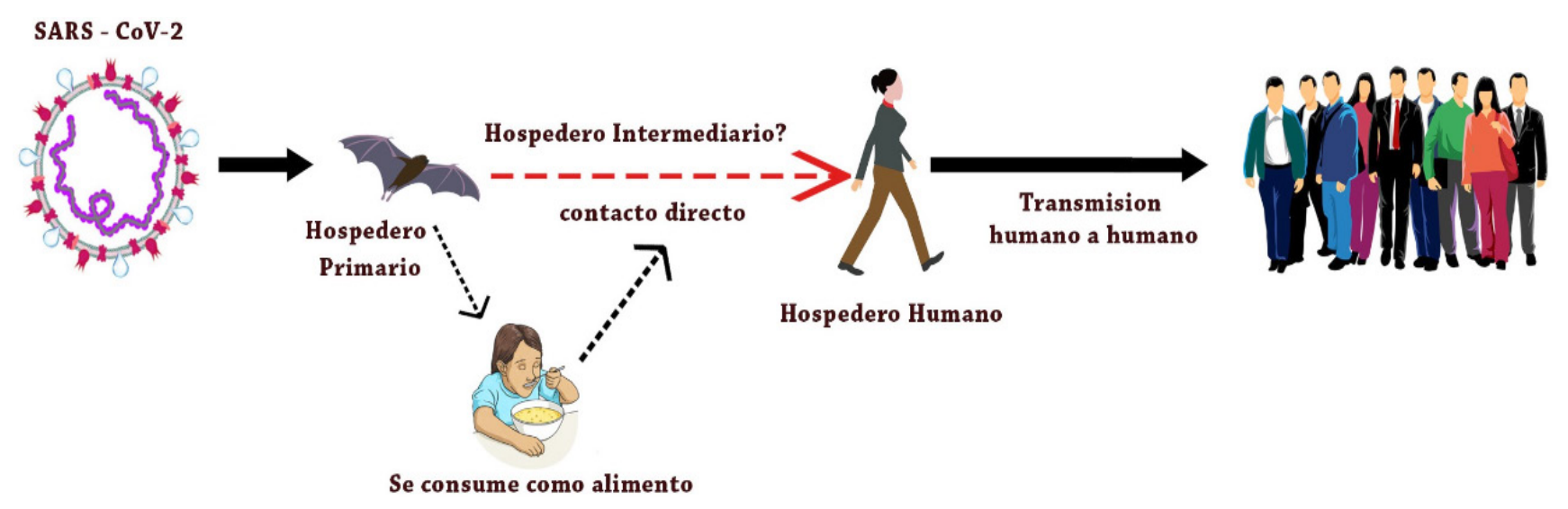

Fig. 2 Posible modo de transmisión del COVID-19 a los humanos (adaptado de Shereen et al. 2020)

el principal reservorio de los coronavirus es de origen animal. Tal es el caso de los anticuerpos contra SARS$\mathrm{CoV}$ que se encontraron en murciélagos del género Rhinolophus que, que sugieren a estos últimos como la fuente de réplica viral (Shi y Hu 2008). Asimismo, en un estudio reciente, se detectaron anticuerpos contra el MERS en murciélagos de la especie Pipistrellus y Perimyotis, determinando que estos son los anfitriones claves y el medio de transmisión del virus (Annan et al. 2013), por lo que se aduce que probablemente el SARS-CoV-2 fue transmitido del murciélago al humano, ya sea por contacto directo o a través de un intermediario (Fig. 2).

Se considera que el virus se propaga de persona a persona cuando estas se encuentran en contacto cercano o directo (menos de 2 metros), a través de gotículas respiratorias que se producen cuando una persona infectada habla, tose o estornuda, siendo inhaladas por quienes se encuentran a una distancia próxima (CDC 2020a). Van Doremalen et al. (2020) y Kampf et al. (2020), en sus estudios, demostraron que el SARS-CoV-2 puede persistir en cartón (24-48 h), plástico (72 h) y acero inoxidable (72 h). No obstante, aún se continúa estudiando el contagio por contacto con superficies u objetos inanimados (CDC 2020b).

\subsection{Síntomas}

La media del período de incubación del virus, desde la exposición hasta el inicio de los síntomas, es de 4 a 5 días. El $97.5 \%$ de los pacientes presentarán síntomas dentro de los 11.5 días después de la infección (Lauer et al. 2020).

Hasta la fecha, se ha demostrado que existen seis tipos distintos de COVID-19, cada uno de los cuales se distingue por un grupo de síntomas. Los investigadores sugieren que esta clasificación puede utilizarse para predecir la necesidad de asistencia respiratoria en COVID-19 severo. Estos seis tipos y sus síntomas se enumeran a continuación:

a. Tipo I o "Parecido a la gripe" sin fiebre: dolor de cabeza, pérdida del olfato, dolores musculares, tos, dolor de garganta, dolor en el pecho, sin fiebre

b. Tipo II o "Semejante a la gripe" con fiebre: dolor de cabeza, pérdida del olfato, tos, dolor de garganta, ronquera, fiebre, pérdida del apetito

c. Tipo III o Gastrointestinal: dolor de cabeza, pérdida del olfato, pérdida del apetito, diarrea, dolor de garganta, dolor en el pecho, sin tos 
d. Tipo IV o Nivel uno severo, fatiga: dolor de cabeza, pérdida del olfato, tos, fiebre, ronquera, dolor de pecho, fatiga

e. Tipo V o Nivel dos grave, confusión: dolor de cabeza, pérdida del olfato, pérdida del apetito, tos, fiebre, ronquera, dolor de garganta, dolor de pecho, fatiga, confusión, dolor muscular

f. Tipo VI o Nivel tres severo, abdominal y respiratorio: dolor de cabeza, pérdida del olfato, pérdida del apetito, tos, fiebre, ronquera, dolor de garganta, dolor de pecho, fatiga, confusión, dolor muscular, dificultad para respirar, diarrea, dolor abdominal.

De la clasificación anterior, menos del $5 \%$ de los pacientes clasificados en los tipos I, II y III han requerido de asistencia respiratoria. Por el contrario, de un $8 \%$ a $19.8 \%$ de los pacientes clasificados en los tipos IV, V y VI requirieron asistencia respiratoria (Wise 2020).

\subsection{Diagnóstico}

La Organización Mundial de la Salud (OMS) ha propuesto una serie de directrices de laboratorio para la detección y el diagnóstico de la infección. Las muestras deben ser tomadas por personal capacitado $\mathrm{y}$ teniendo en cuenta todas las instrucciones de bioseguridad y el uso adecuado del equipo de protección personal, así como el correcto lavado de manos y el uso de bata, respirador (N95 o FFP2), gafas y guantes (OMS 2020b).

Las muestras recomendadas para la detección del SARS-CoV-2 son las obtenidas de las vías respiratorias bajas como esputo, el lavadobroncoalveolaryel aspirado traqueal. Sin embargo, cuando esto no es posible, las muestras obtenidas del tracto respiratorio superior también son útiles, como hisopados nasofaríngeos y/u orofaríngeos. Estas muestras deben mantenerse refrigeradas $\left(4-8^{\circ} \mathrm{C}\right)$ y enviarse al laboratorio, donde se procesarán dentro de las próximas 24-72 horas de la toma. Por el contrario, si no se pueden enviar las muestras dentro de este período, se recomienda congelarlas a $-70{ }^{\circ} \mathrm{C}$ hasta que se envíen, manteniendo la cadena de frío (OPS/OMS 2020; OMS 2020b).

Los ensayos de laboratorio utilizados para la detección del COVID-19 se pueden clasificar en: (a) métodos moleculares, (b) métodos serológicos y (c) detección de antígenos.

a. Métodos moleculares. La Reacción en Cadena de la Polimerasa (PCR, Polymerase Chain Reaction, por sus siglas en inglés) se considera el "estándar de oro" para la detección de algunos virus. En el caso del SARSCoV-2, por ser un virus tipo ARN, se utiliza específicamente la PCR de Transcriptasa Inversa (RT) en tiempo real (RT-PCR, Reverse Transcription Polymerase Chain Reaction, por sus siglas en inglés). La RT es una enzima que sintetiza $\mathrm{ADN}$ a partir de la molécula de ARN viral purificada. Posteriormente, el ADN viral obtenido se mezcla con cebadores, nucleotidos y ADN polimerasa. A dicha mezcla, se le adiciona una sustancia marcada con un fluoróforo que permita medir la tasa de generación de uno o más productos específicos. El termociclador provisto de sensores de fluorescencia (aparato que amplifica el ADN), tras excitar el fluoróforo de la muestra a una longitud de onda apropiada, genera las gráficas en tiempo real (Fig. 3). No obstante, esta técnica presenta desventajas, como la cantidad de horas que se demora para obtener los resultados. El diagnóstico mediante este método es, por tanto, "lento" en la situación actual, en la que se necesitan resultados rápidos (Wan et al. 2020; Brunning 2020; Grupo de Nanobiosensores y Aplicaciones 


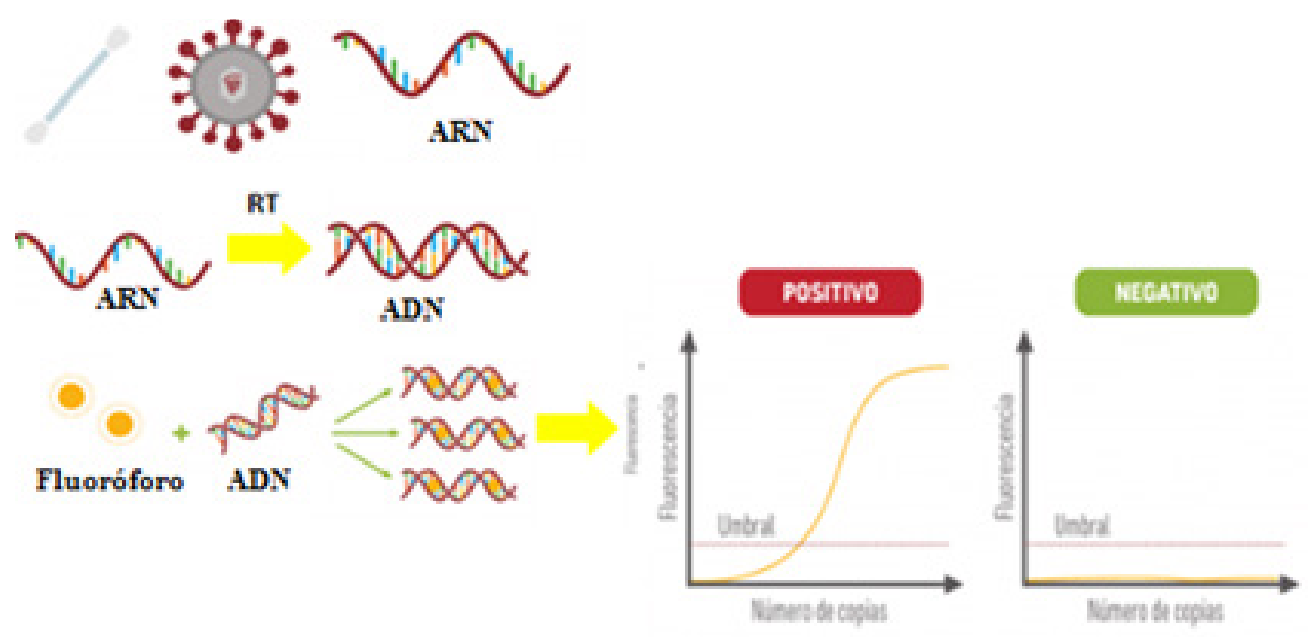

Fig. 3 Procedimiento del RT-PCR para la detección del COVID-19 (adaptado de Brunning (2020))

Bioanalíticas et al. 2020). Esta prueba presenta una especificidad y sensibilidad máxima del $100 \%$ y $84.9 \%$, respectivamente (Padhye 2020).

b. Métodos serológicos. Estas pruebas detectan la presencia de dos inmunoglobulinas: la Inmunoglobulina M (IgM), indicativo de la presencia del virus (infección aguda) y la Inmunoglobulina $\mathrm{G}$ ( $\mathrm{IgG}$ ), indicativo de infecciones pasadas. En definitiva, las pruebas serológicas pueden proporcionar información valiosa respecto a una infección activa o a un contagio previo. Puede ser, por tanto, una herramienta de diagnóstico masivo, sobre todo para detectar pacientes asintomáticos. En estas pruebas, se utiliza un total de $20 \mu \mathrm{L}$ de sangre del paciente sospechoso de portar el virus, la cual se coloca en la parte inferior del dispositivo, agregándose un total de tres gotas de solución tampón (tampón PBS $10 \mathrm{mM}$ ) para conducir por capilaridad la muestra a lo largo de la franja. La prueba completa tardará unos 15 minutos en finalizar. La interpretación de resultados los podemos ver en la Fig. 4 (Grupo de Nanobiosensores y Aplicaciones
Bioanalíticas et al. 2020). Esta prueba presenta una especificidad y sensibilidad máxima del $95 \%$ y $91 \%$, respectivamente (Li et al. 2020). También se puede utilizar la prueba de detección de antígenos en combinación con la PCR. En la Tabla 1, se muestra la interpretación de los resultados de ambas pruebas.

c. Detección de antígenos. La Administración de Alimentos y Medicamentos de los Estados Unidos (FDA, Food and Drug Administration, por sus siglas en inglés) ha emitido la primera autorización de emergencia para una prueba de antígenos en la detección del SARS-CoV 2, llamada Sofía 2 SARS Antigen FIA (FDA 2020). La prueba se trata de una un ensayo "sandwich" que combina la inmunofluorescencia para su uso con el analizador Sofía 2. El objetivo es la detección cualitativa del antígeno proteico de la nucleocápside del SARS-CoV-2. Esta prueba contiene un cassette de prueba (donde se lleva a cabo la reacción de inmunofluorescencia), reactivo de extracción, tubos de ensayo, pipetas estériles con capacidad de $120 \mu \mathrm{L}$ y el aparato Sofía 2. El procedimiento que se debe realizar 


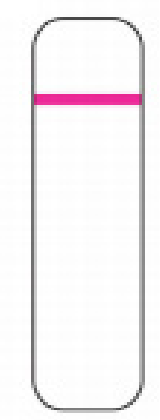

Negativo

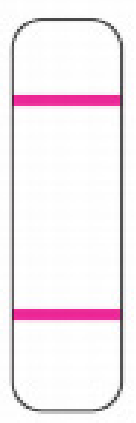

IgM +

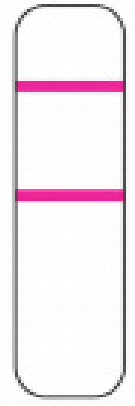

IgG +

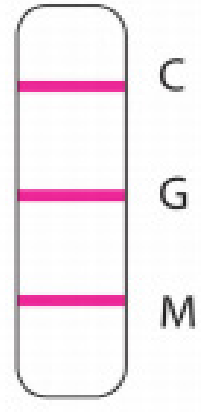

IgM/IgG +

Fig. 4 Ilustración esquemática de la prueba rápida de anticuerpos combinados SARS-CoV-2 IgM-IgG. IgM+: Infección activa, IgG+: Infección pasada o curada y las IgM/IgG +: Enfermedad en evolución (Imagen tomada de Li et al. (2020))

Tabla 1 Interpretación de resultados en pacientes con la COVID-19. Información obtenida del Laboratorio Centro de Diagnóstico Clínico ( 2020) en Tegucigalpa, Honduras, 2020

\begin{tabular}{lllll} 
& \multicolumn{2}{c}{ Tipo de prueba } & & Significado clínico \\
\hline & PCR & IgM & IgG & \\
+ & - & - & Negativo \\
+ & - & - & Periodo de ventana \\
+ & + & - & Estadio temprano de la infección \\
+ & + & + & Fase activa de la infección \\
- & - & + & Fase final de la infección \\
- & + & - & Estadio temprano con falso negativo. Confirmación por PCR \\
- & - & + & Infección pasada y curada
\end{tabular}

se muestra en la Fig. 5. Primero, se prepara el reactivo de extracción. Seguidamente, se obtiene del paciente sospechoso de COVID-19 y con ayuda de un hisopo estéril, una muestra nasal o nasofaríngea. Esta debe introducirse en el tubo conteniendo el reactivo de extracción y se deja en contacto durante un mínimo de 1 minuto, haciendo rotar el cabezal del hisopo contra el interior del tubo mientras se retira. Posteriormente, con ayuda de una pipeta de capacidad de $120 \mu \mathrm{L}$, se toma el contenido del tubo (con la muestra) y se coloca en el casette de prueba, el cual debe insertarse en el analizador Sofía 2. Este aparato escanea las proteínas que 


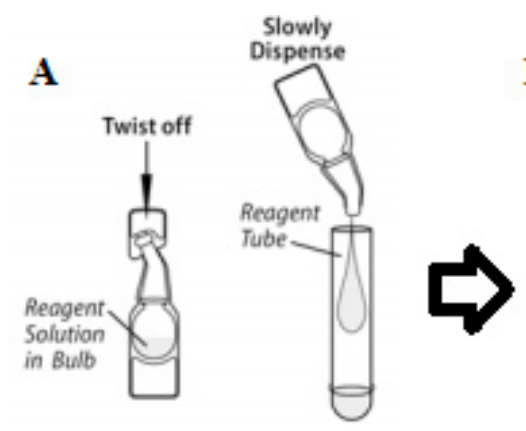

B
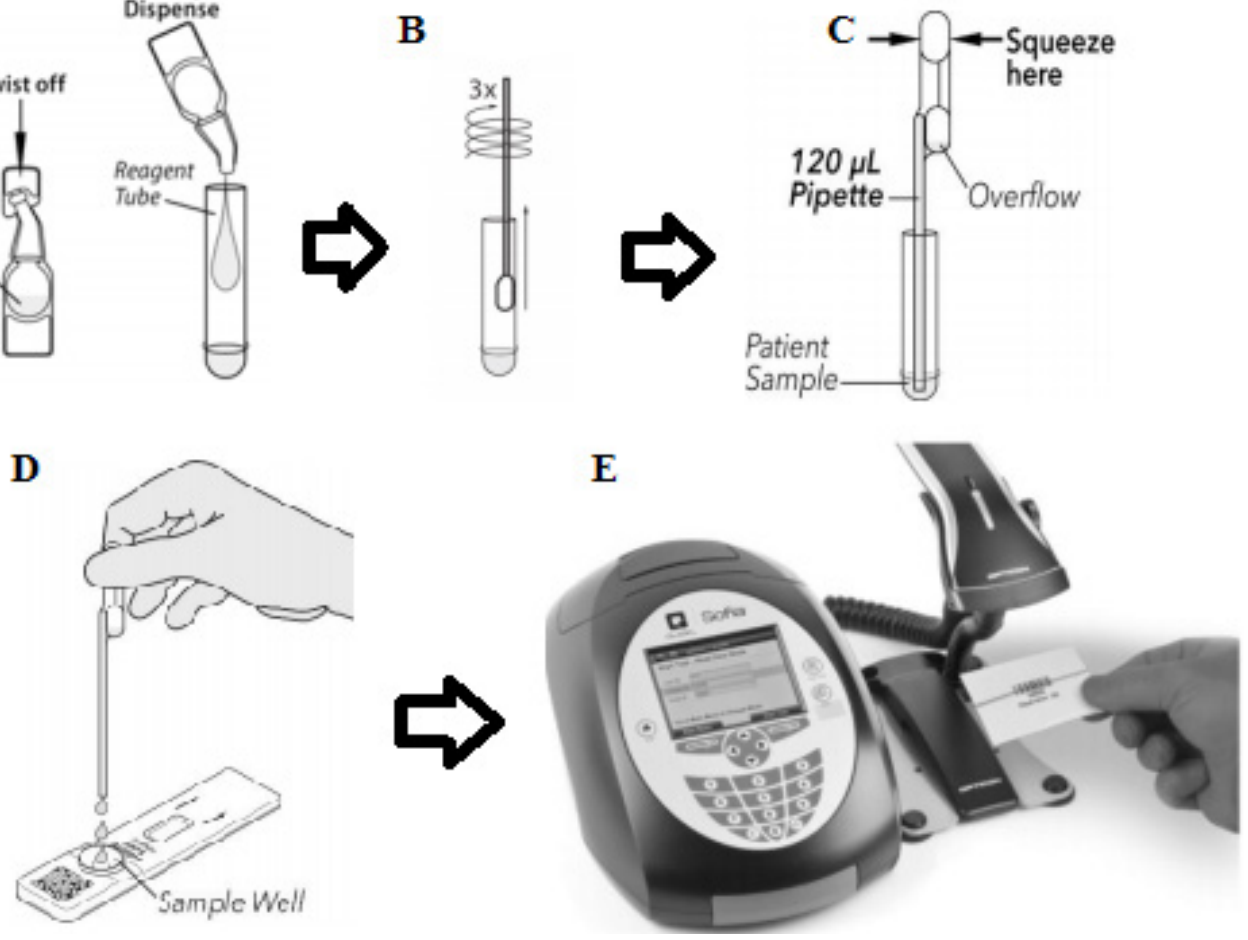

Fig. 5 Procedimiento de la prueba de detección de antígenos con Sofía 2 SARS Antigen FIA (adaptado de la FDA (2020))

se pueden encontrar en la superficie del virus o en su interior, utilizando algoritmos patentados para analizar los datos, interpretar señales y determinar los resultados automáticamente en un tiempo máximo de 15 minutos. Esta prueba presenta una especificidad y sensibilidad máxima del $100 \%$ y $80 \%$, respectivamente (FDA 2020).

\subsection{Patogénesis del Coronavirus}

Se conoce que los coronavirus contienen en su estructura una proteína llamada Spike (S) o espina, que se une a los receptores de la enzima ACE2 del hospedero (ACE2, Angiotensin-converting enzyme 2, por sus siglas en inglés) (Fig. 6). La proteína $\mathrm{S}$ se divide en dos subunidades, $\mathrm{S} 1$ y S2, por una proteasa extracelular. Mientras S1 se una a ACE2, S2 se escinde aún más y es activada por la TMPRSS2 (Proteasa Transmembrana de Serina 2 Asociada a la Superficie del Huesped). Juntas, estas acciones dan como resultado la fusión del virus en la membrana celular del hospedero (Hoffman et al. 2020). Asimismo, la activación de las proteinasas de $\mathrm{S}$ (tripsina y/o furina) liberan los ARN virales al citoplasma, iniciándose así la infección (Li et al. 2005; Kuba et al. 2010).

Las ACE2 se expresan principalmente en las células endoteliales vasculares, el epitelio tubular renal y en las células de Leydig en los testículos. También se expresan en el pulmón, los riñones y el tracto gastrointestinal, tejidos que albergan SARSCoV-2 (Ksiazek et al. 2003; Leung et al. 2003).

\section{TRATAMIENTO FARMACOLÓGICO}

Actualmente, no existen suficientes evidencias científicas que comprueben la eficacia de los tratamientos frente a la infección causada por el SARS-CoV-2 en el organismo humano. Esto genera una importante preocupación, debido al rápido avance de la infección a nivel mundial, ya que entre 


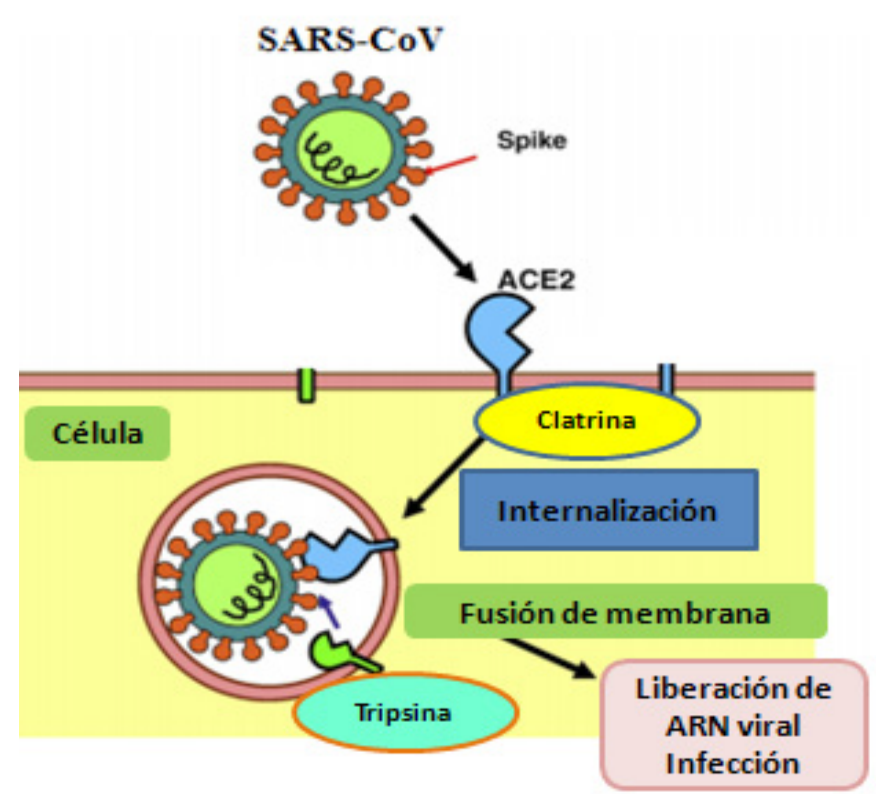

Fig. 6 Patogénesis del Coronavirus. Entrada del virus a la célula del hospedero (adaptado de Kuba et al. (2010))

un 5-10\% de los infectados puede tener un curso grave de la enfermedad, por lo cual la estrategia actual de tratamiento continúa fundamentándose en la terapia de soporte y prevención de complicaciones (Kamps y Hoffmann 2020). Paralelamente, para contribuir con evidencia científica confiable que ayude en la toma de decisiones clínicas, existen importantes esfuerzos en la realización de ensayos in-vitro al igual que ensayos clínicos controlados y aleatorizados. Estos toman, como punto de partida, fármacos que han demostrado previamente actividad antiviral contra otros virus similares como el SARS y el MERS. Se estudian también fármacos que, por su mecanismo de acción y experiencia de uso en otras patologías, podrían utilizarse como tratamiento para COVID-19. El abordaje farmacológico conlleva diferentes estrategias. Se puede impedir directamente la replicación viral al inhibir la entrada del virus o bloquear enzimas responsables de su replicación. Por otro lado, también se utilizan estrategias diseñadas para modular el sistema inmune humano, ya sea aumentando la respuesta innata antiviral natural o inhibiendo los procesos inflamatorios exacerbados que pueden causan daño pulmonar (Tu et al. 2020).

\subsection{Fármacos dirigidos a inhibir la replicación viral}

\section{Hidroxicloroquina}

Es un antimalárico que puede bloquear la infección vírica al incrementar el $\mathrm{pH}$ del endosoma temprano, requerido para la fusión de la membrana entre el virus y la célula huésped. Recientemente, se ha demostrado que la hidroxicloroquina inhibe, de manera específica, la replicación del SARS-CoV al interferir con la glucosilación de su receptor celular, ACE2 (Vincent et al. 2005). Cierta confusión y resultados no concluyentes se han obtenido hasta la fecha con el uso de este fármaco. El pequeño ensayo clínico abierto no aleatorio de Gautret et al. (2020) demostró un efecto positivo en combinación con azitromicina, y por otra parte, estudios recientes no demuestran un mayor beneficio en la disminución de la mortalidad respecto al riesgo de su uso como tratamiento (Tang et al. 2020; Chen et al. 2020a; Geleris et al. 2020), ni como la profilaxis de COVID-19 (Boulware et al. 2020). Lo 
que sí está claro es que el uso indiscriminado de este medicamento puede exponer a los pacientes a daños poco frecuentes pero potencialmente mortales, como arritmias, reacciones cutáneas o fallo hepático (Kamps y Hoffman 2020). Por esta razón, la recomendación de la FDA ha sido que su uso en tratamiento de la COVID-19 se realice en entornos hospitalarios controlados y que se puedan llevar a cabo ensayos clínicos controlados y aleatorizados para conocer su efectividad y seguridad en el contexto de la pandemia (Medina y Moncada 2020). Resta esperar los resultados de los ensayos clínicos que se desarrollan actualmente en todo el mundo con este fármaco.

\section{Lopinavir/Ritonavir}

Ambas moléculas han demostrado actividad inhibiendo la proteasa del VIH-1, siendo el responsable principal de esta acción el lopinavir, el cual presentó mayor potencia inhibitoria in-vitro, (Choy et al. 2020). En cambio, el ritonavir se utiliza principalmente como potenciador farmacocinético, mejorando los parámetros del primero (Hsu et al. 2003). Si bien es cierto que los coronavirus codifican una clase enzimática diferente de proteasa, denominada cisteína proteasa, algunos autores avalan la evidencia teórica de que dichos fármacos también inhiben la proteasa coronaviral 3CL1pro (Chu et al. 2004). En esa línea, una serie de estudios in-vitro, invivo y ensayos clínicos realizados en SARS y MERS demostraron su eficacia contra esta clase de virus. De hecho, se evaluaron in-vitro ambos fármacos, específicamente contra el SARS-CoV-2, y se encontró que únicamente el lopinavir inhibió la replicación de este virus eficazmente $\left(\mathrm{EC}_{50} \sim 26.63 \mu \mathrm{M}\right)$, no así el ritonavir $\left(\mathrm{EC}_{50}>100 \mu \mathrm{M}\right)$ (Choy et al. 2020). Cabe destacar que la combinación de LPV/RTV más ribavirina demostró ser efectiva contra el SARS-CoV in-vitro (Jean et al. 2020). Por otra parte, el ensayo clínico contra COVID-19 NCT04252885 utilizó la combinación de lopinavir/ritonavir en pacientes con COVID-19 leve y moderado, sin embargo, pocos beneficios fueron observados (Agostini et al. 2018). En otro ensayo ChiCTR2000029308, realizado en pacientes con COVID-19 grave, no se observaron beneficios más allá de la atención estándar (Cao et al. 2020), ni se encontró diferencia entre la disminución de la carga viral y la mejoría clínica.

\section{Ivermectina}

Fue aprobado por la FDA como antiparasitario y ha demostrado poseer actividad antiviral in-vitro contra el VIH y contra el virus del dengue (Wagstaff et al. 2012). Actúa disociando el heterodímero IMP $\alpha /$ $\beta 1$ preformado, el cual es un transportador nuclear de proteínas virales, proceso esencial en el ciclo de replicación e inhibición de la respuesta antiviral del huésped. De acuerdo con lo planteado por Caly et al. (2012), la terapéutica sobre este proceso puede ser viable para el tratamiento de los virus de ARN. Mediante un estudio in-vitro, se demostró la capacidad del fármaco para reducir el ARN viral hasta 5,000 veces después de $48 \mathrm{~h}$ de infección con SARS-CoV-2 con una concentración inhibitoria $\mathrm{IC}_{50} \sim 2 \mu \mathrm{M}$ (Caly et al. 2020). Sin embargo, modelos farmacocinéticos demuestran que la dosis recomendada para este fármaco no alcanza las concentraciones reportadas contra el virus SARS-CoV-2 in-vitro, por lo que es indispensable llevar a cabo ensayos clínicos para comprobar la eficacia y seguridad de esta molécula en humanos para el tratamiento de la COVID-19.

\section{Remdesivir}

Es un profármaco que puede incorporarse al ARN viral inhibiendo la ARN-polimerasa, lo que detiene la replicación del genoma del SARS-CoV-2. El remdesivir ha sido previamente estudiado en ensayos clínicos contra el virus del Ébola (Mulangu et al. 2019), así como contra SARS-CoV y MERS-CoV 
en estudios in-vitro e in-vivo (Wang et al. 2020a), encontrándose resultados favorables. Recientemente, se ha evaluado su actividad in-vitro contra SARSCoV-2, demostrando que inhibe la replicación de este virus en células Vero E6 con $\mathrm{IC}_{50}$ por debajo de $100 \mu \mathrm{M}$ (Choy et al. 2020). Es considerado el agente antiviral más prometedor hasta el momento (Kamps y Hoffmann 2020), fundamentado por sus particulares características estructurales, potente actividad viral contra el SARS-CoV-2 y seguridad en la experiencia clínica contra el virus del Ébola (Jorgensen et al. 2020). De acuerdo con lo reportado por Holshue et al. (2020), el remdesivir mostró buen resultado en un paciente hospitalizado en Estados Unidos por COVID-19. Los ensayos clínicos en los que se encuentra este estudio son NCT04252664 y NCT04257656, ambos ensayos clínicos aleatorizados.

\section{Favipivir}

Es un análogo del remdesivir, lo que le permite inhibir la ARN polimerasa (Furuta et al. 2017). Pese a que ha sido aprobado para la influenza, su uso contra el SARS-CoV-2 ha sido mínimo en comparación al fármaco anterior. Se le ha utilizado en conjunto con el interferón $\alpha$ gracias al efecto sinérgico esperado de la inhibición viral y la mejora en el sistema inmune. De allí que en mayo del 2020, fue probado como el primer fármaco anti-COVID-19 bajo ensayo abierto controlado, nombrado como ChiCTR2000029600, el cual demostró eficacia con efectos secundarios mínimos.

\section{Umifenovir}

También conocido como arbidol, este fármaco se ha utilizado contra los virus de la influenza y los arbovirus (Kadam y Wilson 2016), dirigido específicamente a la hemaglutinina (HA), que es la glucoproteína principal que se encuentra en la superficie del virus de la gripe. En el caso del SARS-CoV-2, se ha demostrado que reviene la fusión de la membrana viral con la endosoma de la célula al impedir la interacción entre la proteína $\mathrm{S}$ y la ACE2. Los estudios NCT04260594 y NCT04255017 se tratan de ensayos clínicos aleatorizados dirigidos, utilizándose el fármaco como agente único. Asimismo, un estudio reciente comparó el uso del arbidol con favipiravir (ChiCTR2000030254) y este último demostró ser más efectivo contra COVID-19 (Chen et al. 2020b).

\section{Enzima convertidora de angiotensina recombinante}

Dado que la proteína S del SAR-CoV-2 interactúa con la ACE2 celular, se espera que la enzima convertidora de angiotensina humana recombinante soluble (rhACE2) bloquee la entrada del virus al unirse esta al virus en lugar de la ACE2 celular. Asimismo, la administración de rhACE2 puede disminuir el nivel sérico de angiotensina II al dirigir el sustrato lejos de la enzima. Esto podría evitar una mayor activación del receptor ACE2 y, por lo tanto, preservar la integridad vascular pulmonar y prevenir el síndrome de distrés respiratorio agudo (SDRA) (Khan et al. 2017). Un pequeño estudio piloto, identificado como NCT04287686, está evaluando el papel biológico y fisiológico de rhACE2 en la neumonía causada por la enfermedad COVID-19, especialmente como tratamiento del SDRA.

\section{Homoharrigtonina}

Es un alcaloide vegetal con actividad antitumoral, a partir del cual existe una forma semisintética denominada omacetaxina, aprobada por la FDA como medicamento para el tratamiento de la leucemia mieloide crónica (Dong et al. 2018). Este fármaco demostró previamente actividad antiviral contra diferentes virus, incluyendo algunos coronavirus, por lo cual se evaluó su actividad antiviral inhibitoria in-vitro contra el SARS-CoV-2, encontrándose que inhibe este virus eficazmente $\left(\mathrm{IC}_{50} 2.10 \mu \mathrm{M}\right)$ (Choy 
et al. 2020). Sin embargo, estudios farmacocinéticos indican que con las dosis recomendadas, se alcanza una $\mathrm{IC}_{50}$ muy por debajo de las reportadas contra el virus SARS-CoV-2 in-vitro, por lo cual es indispensable evaluar su seguridad y eficacia mediante estudios in vivo.

\subsection{Fármacos que potencian la respuesta inmunológica innata antiviral}

\section{Teicoplanina}

Es un antibiótico utilizado para tratar la infección por estafilococos. Previamente, mostró eficacia para inhibir la primera etapa del ciclo viral del coronavirus MERS en células humanas (Baron et al. 2020), por lo cual se considera como un potencial tratamiento para pacientes con COVID-19. Asimismo, también demostró inhibir el SARS-Cov-2 in-vitro con una $\mathrm{IC}_{50}$ de $1.66 \mu \mathrm{M}$, que es mucho más baja que la concentración clínica habitual. Esto podría sugerir que con la dosis empleada habitualmente, es posible tratar a pacientes con infección por SARS-CoV2. Además, es importante considerar también su buen perfil de seguridad, con lo cual es posible optimizar dosis de ser necesario (Zhang et al. 2020a). A la vista de estos resultados, es necesario comprobar su eficacia y seguridad mediante ensayos clínicos controlados y aleatorizados, ya que se han reportado algunas experiencias con datos alentadores, pero con limitaciones metodológicas importantes (Ceccarelli et al. 2020).

\section{Emetina}

Este fármaco actúa como inhibidor de la síntesis de proteínas. Fue aprobado como medicamento para el tratamiento de la amebiasis. Por otra parte, se ha demostrado que posee actividad antiviral contra una amplia variedad de virus ADN y ARN, incluidos SARS-CoV y MERS-CoV. Por esta razón, Choy et al. (2020) evaluaron recientemente su actividad antiviral in-vitro contra el SARS-CoV-2, encontrando que puede inhibir efectivamente la replicación del virus. Sin embargo, las concentraciones terapéuticas plasmáticas reportadas previamente se encuentran por debajo de la $\mathrm{EC}_{50}$ contra el virus SARS-CoV-2 in-vitro $\left(\mathrm{EC}_{50}\right.$ de $\left.0.46 \mu \mathrm{M}\right)$. Como una propuesta para reducir la concentración efectiva de compuesto individual por debajo de la concentración plasmática terapéutica máxima, estos investigadores evaluaron el efecto combinatorio de remdesivir y emetina invitro, y observaron que puede lograr un $64.9 \%$ de inhibición del rendimiento viral con una $\mathrm{EC}_{50}$ de $0.195 \mu \mathrm{M}$, siempre realizando la recomendación que esto debe ser evaluado in-vivo.

\subsection{Fármacos que potencian la respuesta inmunológica innata natural \\ Interferón recombinante}

Aquellas células infectadas con algún tipo de virus, como mecanismo de defensa, secretan interferones tipo I, alfa y beta; de allí que estas sustancias han demostrado efecto antiviral contra el SARS-CoV (Cinatl et al. 2003) y el MERS-CoV (Sheahan et al. 2020; Cinatl et al. 2003). Los actuales ensayos clínicos, como ser NCT04293887, se centran en la seguridad y eficacia en el tratamiento de la neumonía causada por COVID-19.

\section{Inmunoglobulina}

Es una terapia común en campos de la neurología, dermatología y reumatología, actuando en el sistema inmune dependiente de las dosis. Así, dosis entre 0.2 $-0.4 \mathrm{~g} / \mathrm{kg}$ son utilizadas como terapia de reemplazo en la deficiencia de anticuerpos. Por otra parte, funciones inmunomoduladoras son observadas con dosis de hasta $2 \mathrm{~g} / \mathrm{kg}$, suprimiendo la proliferación de células inflamatorias e inhibiendo la fagocitosis (Jolles et al. 2005). Actuales ensayos clínicos, como 
NCT04261426, están centrados en los efectos suplementarios de las dosis bajas de Ig IV $0.5 \mathrm{~g} / \mathrm{kg}$ durante 5 días.

\section{Anticuerpos neutralizantes específicos de SARS- CoV-2}

Este tipo de tratamiento es un enfoque a largo plazo. Sin embargo, la especificidad en contra del COVID-19 lo hace ser esperanzador, además de mostrar éxito en un pasado reciente contra el virus del Nilo Occidental (Tsioris et al. 2015). Algunas compañías norteamericanas se encuentran desarrollando un anticuerpo capaz de neutralizar el SARS-CoV-2 en pacientes infectados, para lo cual se han analizado más de 5 millones de células inmunes de los primeros pacientes en sufrir COVID-19 y que se lograron recuperar.

\section{Zinc}

Este es un mineral esencial para el cuerpo humano. Los experimentos in-vitro demuestran que el zinc posee actividad antiviral a través de la inhibición de la ARN polimerasa del virus, presenta actividad antiinflamatoria y también puede reducir el riesgo de coinfección bacteriana. No obstante, se requieren ensayos clínicos en humanos que compruebe su efectividad frente a la COVID-19 (Skalny et al. 2020).

\subsection{Fármacos que controlan la respuesta exacerbada a la enfermedad}

\section{Metilprednisolona}

Es sabido que los glucocorticoides sistémicos pueden prolongar la eliminación viral, de allí que sean contraindicados en la infección por SARS-CoV-2. Sin embargo, dado que la patogénesis subyacente de la neumonía por COVID-19 se compone tanto del daño directo causado por el virus como de la respuesta inmune excesiva del huésped, se ha planteado que la administración de este corticosteroide suprimiría las reacciones inmunes no deseadas (Wang et al. 2020b). Dicho planteamiento es aún controvertido, por lo que algunos estudios seencuentran explorandosuefectividad y seguridad (NCT04273321, NCT04263402).

\section{Tocilizumab}

La interleucina-6(IL-6), Factor de necrosis tumoral (TNF- $\alpha$ ) e IL-1 son las citocinas proinflamatorias más importantes en el cuerpo humano. La IL-6 es el factor predictivo de mal pronóstico en pacientes que sufren SDRA (Voiriot et al. 2017). Es un anticuerpo monoclonal humanizado recombinante, aprobado por la FDA para el tratamiento de artritis reumatoide. Se une a los receptores de interleucina- 6 , bloqueando la señalización de IL-6 y su respuesta inflamatoria mediada (Zhang et al. 2020b), por lo cual se ha considerado en el tratamiento de la COVID-19, especialmente en pacientes con riesgo de tormenta de citocinas. En este sentido, se han realizado algunos estudios para evaluar el uso de tocilizumab en pacientes con diagnostico COVID-19 crítico o grave, con resultados favorecedores respecto a su eficacia en ese estadio de la enfermedad (Luo et al. 2020; Zhang et al. 2020b). Sin embargo, estos datos aun no son contundentes. Actualmente, se han puesto en marcha varios ensayos clínicos con este fármaco, en los que se emplea individualmente (ChiCTR2000029765) y en combinación con otros fármacos (ChiCTR2000030442,

\section{ChiCTR2000030894).}

\section{Talidomida}

Debido a sus efectos anti angiogénico, antiinflamatorio y antifibrótico recientemente descubiertos, este antiguo fármaco comercializado después de la Segunda Guerra Mundial disminuye la síntesis del TNF-alfa, por lo que se ha utilizado como tratamiento para múltiples enfermedades inflamatorias (Vargesson 2015). Estudios actuales se están llevando a cabo analizando los efectos inmunomoduladores capaces 
de disminuir la lesión pulmonar causada por un exceso de respuesta inmunitaria al virus SARS-CoV-2 (NCT04273529, NCT04273581).

\section{Heparina}

La infección por la COVID-19 se ha asociado directamente con estados protrombóticos (Guan et al. 2020). Se ha asociado el uso de la heparina de bajo peso molecular en pacientes infectados, demostrando efectos beneficiosos. También podría ser utilizado como profiláctico (Thachil 2020).

\section{TRATAMIENTO DE LACOVID-19 ENHONDURAS}

Actualmente, se está realizando el estudio "Solidaridad”, el cual consiste en un ensayo clínico internacional, puesto en marcha por la OMS y sus asociados, en donde se comparan opciones de tratamiento y que tiene como objetivo final el descubrir con rapidez si alguno de los medicamentos estudiados retrasa la progresión de la enfermedad o mejora la tasa de supervivencia. Los medicamentos que se están ensayando en este estudio son los siguientes: remdesivir, liponavir/ritonavir, liponavir/ritonavir combinado con interferon alfa e hidroxicloroquina (cloroquina). La información de estos medicamentos se encuentra definida anteriormente en este documento. Se están esperando resultados de este estudio (OMS 2020c).

En Honduras, a través de la Secretaria de Salud, se oficializó en abril del 2020 el protocolo de manejo clínico del paciente adulto con COVID-19 según las etapas de la enfermedad en los distintos niveles de atención (Secretaria de Salud de Honduras 2020b). En junio de este mismo año, fue publicada una segunda versión revisada (Secretaria de Salud de Honduras 2020c) que incluía los mismos medicamentos, y el documento de lineamientos para el manejo clínico ambulatorio de pacientes con COVID-19 según estadios de la enfermedad (Secretaria de Salud de Honduras 2020a). En relación a los medicamentos que conforman estos protocolos, hemos mencionado aquellos que permanecen o han sido evaluados científicamente para el tratamiento de la COVID-19 a nivel nacional e internacional $y$ que cuentan con evidencia documentada, ya sea con resultados favorables o poco alentadores, como son: ivermectina, hidroxicloroquina, tocilizumab y metilprednisolona. Estos han sido discutidos previamente, incluyendo los reportes de ensayos in-vitro para la evaluación de la acción inhibitoria del SARS-CoV-2 en algunos de estos. Cabe mencionar que hasta el momento de esta revisión, no existen reportes científicos locales sobre los resultados de la implementación de estos protocolos o sobre el comportamiento de estos medicamentos en la población hondureña que ha sido infectada y tratada con los mismos, lo cual resulta relevante para la obtención de los mejores resultados en el control de la enfermedad.

Dentro de los protocolos de tratamiento que no han sido aún avalados científicamente, cabe mencionar que el gobierno de la República de Honduras, durante este año, ha elaborado una propuesta de manejo de primera línea del COVID-19. Sin embargo, este tratamiento, hasta la fecha, no se encuentra publicado. Lo denominan el tratamiento MAIZ, un acrónimo en el cual se detallan a continuación cuatro medicamentos:

M: Microdacyn

A: Azitromicina

I: Ivermectina

Z: Zinc

A este protocolo de tratamiento, también se ha agregado el acetaminofen y la hidroxicloroquina (Gobierno de Honduras 2020).

De los cuatro medicamentos anteriores, dos han causado polémica a nivel nacional y mundial. Primero, 
el microdacyn (ácido hipocloroso e hipoclorito de sodio), solución electrolizada indicada para utilizarse en el desbridamiento, la irrigación y la hidratación de las heridas, úlceras, cortes, abrasiones y quemaduras de naturaleza tanto aguda como crónica, es efectivo en procesos bacterianos y virales. No obstante, no se ha probado su eficacia en el tratamiento de la COVID-19 (Microdacyn 2020). Asimismo, es importante manejar la información toxicológica de este producto. Segundo, hay controversia con el uso de la azitromicina, ya que en un estudio realizado por Cavalcanti et al (2020), esta molécula no ayudó a mostrar mejorías en los pacientes que participaron en el ensayo clínico. Por el contrario, en el estudio realizado por Arshad et al. (2020), el tratamiento con azitromicina mostró una disminución en la mortalidad de los pacientes. Es por ello que se aconseja seguir los estudios con este fármaco.

Del mismo modo que el protocolo MAIZ, se habla del tratamiento denominado "CATRACHO", el cual fue creado por un médico hondureño que reside en los Estados Unidos de Norteamérica. Está conformado por medicamentos como: colchicina, antiinflamatorios, tocilizumab, ivermectina, anticoagulantese hidroxicloroquina. Este método, se supone, contrarresta infecciones inflamatorias y de hipercoagulación que pueden conllevar una trombosis y es aplicado en la etapa de hospitalización. Consiste en el suministro de antivirales, antiinflamatorios, anticoagulantes y terapia de sistema con alto flujo de oxígeno. Al igual que el tratamiento MAIZ, es necesario que estos protocolos sean publicados para que puedan ser científicamente válidos (Criterio.hn 2020). Estos protocolos de tratamiento deben ser dispensados bajo supervisión médica.

\section{DISCUSIÓN}

Hasta la fecha, no existen fármacos o vacunas específicas para SARS-CoV-2 y el tratamiento clínico de la COVID-19 ha sido limitado a la terapia de soporte y prevención de complicaciones. Por lo tanto, hay una necesidad urgente de desarrollar una vacuna segura y estable, ya que la transmisión interpersonal del virus podría prevenirse inmunizando a los trabajadores de la salud y la población no infectada.

Si bien es cierto que el descubrimiento de nuevos fármacos conlleva muchos años de estudio (15-20 años), la elección de moléculas ya aprobadas para otras enfermedades es una estrategia prometedora para el tratamiento de la COVID-19. Tal es el caso de todos los fármacos que mencionamos en la presente revisión. Es importante destacar que la mayoría de estos se han identificado mediante: modelos virtuales de detección, líneas celulares o modelos animales, probando su actividad antiviral in-vitro. Por lo tanto, es fundamental llevar a cabo ensayos clínicos controlados y aleatorizados para probar la eficacia y seguridad de los medicamentos en las personas y aumentar significativamente el nivel de evidencia científica disponible.

Conocemos de las dificultades parala implementación de ensayos clínicos, sobre todo en países como Honduras, con serias limitaciones en sus sistemas sanitarios. Esto dificulta los controles y el seguimiento óptimo, ocasionando que el uso compasivo sea el pilar de la atención clínica. Resulta imposible conocer de forma precisa y documentar el beneficio o riesgo que conllevó la utilización de estos medicamentos en la población, con poco aporte además a la ciencia en el país.

\section{REFERENCIAS BIBLIOGRÁFICAS}

Agostini, M. L., Andres, E. L., Sims, A. C., Graham, R. L., Sheahan, T. P., Lu, X., ... \& Ray, A. S. (2018). Coronavirus susceptibility to the antiviral remdesivir (GS-5734) is mediated by the viral polymerase and the proofreading 
exoribonuclease. $m$ Bio, 9(2)._doi: $10.1128 / \mathrm{mBio} .00221-18$ Arshad, S., Kilgore, P., Chaudhry, Z. S., Jacobsen, G., Wang, D. D., Huitsing, K., ... \& Zervos, M. (2020). Treatment with hydroxychloroquine, azithromycin, and combination in patients hospitalized with COVID-19. International Journal of Infectious Diseases, 97, 396-403. doi: 10.1016/j. ijid.2020.06.099

Annan, A., Baldwin, H. J., Corman, V. M., Klose, S. M., Owusu, M., Nkrumah, E. E., ... \& Drexler, J. (2013). Human betacoronavirus 2c EMC/2012-related viruses in bats, Ghana and Europe. Emerging Infectious Diseases, 19(3), 456-459. doi: $10.3201 /$ eid1903.121503

Baron, S. A., Devaux, C., Colson, P., Raoult, D., \& Rolain, J. M. (2020). Teicoplanin: an alternative drug for the treatment of COVID-19? International Journal of Antimicrobial Agents, 55(4). doi: 10.1016/j.ijantimicag.2020.105944

Brunning, A. (2020). Infografías Periódicas: Una Guía para las pruebas de COVID-19. Chemical \& Engineering News. Accesado 28 de mayo de 2020. Disponible en: https:// cen.acs.org/content/dam/cen/98/25/WEB/09825-feature4spanish.pdf

Boulware, D. R., Pullen, M. F., Bangdiwala, A. S., Pastick, K. A., Logfren, S. M., Okafor, E. C., ... \& Hullsiek, K. H. (2020). A Randomized Trial of Hydroxychloroquine as Postexposure Prophylaxis for Covid-19. The New England Journal of Medicine, 383, 517-525. doi: 10.1056/NEJMoa2016638

Caly, L., Wagstaff, K. M., \& Jans, D. A. (2012). Nuclear trafficking of proteins from RNA viruses: Potential target forantivirals? Antiviral Research 95(3), 202-206. doi: 10.1016/j.antiviral.2012.06.008

Caly, L., Druce, J. D., Catton, M. G., Jans, D. A., \& Wagstaff, K. M. (2020). The FDA-approved Drug Ivermectin inhibits the replication of SARS-CoV-2 in vitro. Antiviral Research, 178, 104787. doi: 10.1016/j.antiviral.2020.104787

Cao, B., Wang, Y., Wen, D., Liu, W., Wang, J., Fan, G., ... \& Wang, C. (2020). A Trial of Lopinavir-Ritonavir in Adults Hospitalized with Severe Covid-19. The New England Journal of Medicine, 382(19), 1787-1797. doi: 10.1056/ NEJMoa2001282
Cavalcanti, A. B., Zampieri, F. G., Rosa, R. G., Azevedo, L., Veiga, V. C., Avezum, A., ... \& Berwanger, O. (2020). Hydroxychloroquine with or without Azithromycin in Mild-to-Moderate Covid-19. The New England Journal of Medicine. doi: 10.1056/NEJMoa2019014

Ceccarelli, G., Alessandri, F., d'Ettorre, G., Borrazo, C., Spagnolello, O., Oliva, A., ... \& Venditti, M. (2020). Is teicoplanin a complementary treatment option for COVID-19? The question remains. International Journal of Antimicrobial Agents, 56(2), 106029. doi: 10.1016/j. ijantimicag.2020.106029

CIDBIMENA \& Relaciger (2020). COVID-19 Dashboard by the Center for Systems Science and Engineering. Accesado 07 de septiembre de 20201. Disponible en: http://www.bvs.hn/ COVID-19/index 2.html

CDC (2020a). Enfermedad del coronavirus 2019 (COVID-19): Cómo se propaga el COVID-19. Centros para el Control y la Prevención de Enfermedades. Accesado 22 de mayo de 2020. Disponible en: https://espanol.cdc.gov/coronavirus/2019ncov/prevent-getting-sick/how-covid-spreads.html

CDC (2020b). Enfermedad del coronavirus 2019 (COVID-19):

Síntomas de la enfermedad del coronavirus. Centros para el Control y la Prevención de Enfermedades. Accesado 22 de mayo de 2020. Disponible en: https://espanol.cdc.gov/ coronavirus/2019-ncov/symptoms-testing/symptoms.html

Chen, C., Zhang, Y., Huang, J., Yin, P., Cheng, Z., Wu, J., ... \& Wang, X. (2020a). Favipiravir versus Arbidol for COVID-19: A Randomized Clinical Trial. medRxiv. doi: $\underline{10.1101 / 2020.03 .17 .20037432}$

Chen, J., Liu, D., Liu L., Liu, P., Xu, Q., Xia, L., ... \& Lu, H. (2020b). A pilot study of hydroxychloroquine in treatment of patients with moderate COVID-19. Journal of Zhejiang University Medical Sciences, 49(2). doi: 10.3785/j. issn.1008-9292.2020.03.03

Choy, K. T., Wong, A. Y. L., Kaewpreedee, P., Sia, S. F., Chen, D., Hui, K. P. Y., ... \& Yen, H. L. (2020). Remdesivir, lopinavir, emetine, and homoharringtonine inhibit SARSCoV-2 replication in vitro. Antiviral Research, 178, 104786. doi: $10.1016 /$ j.antiviral.2020.104786 
Chu, C.M., Cheng, V. C. C., Hung, I. F. N., Wong, M. M. L., Chan, K. H., Chan, K. S., ... \& Yuen, K. Y. (2004). Role of lopinavir/ritonavir in the treatment of SARS: Initial virological and clinical findings. Thorax, 59(3), 252-256. doi: $10.1136 /$ thorax.2003.012658

Cinatl, J., Morgenstern, B., Bauer, G., Chandra, P., Rabenau, H., \& Doerr, H. W. (2003). Treatment of SARS with human interferons. The Lancet, 362(9380), 293-294. doi: 10.1016/ s0140-6736(03)13973-6

Criterio.hn (2020). MAIIZ y CATRACHO están siendo utilizados para abrir los comercios. Accesado 16 de agosto de 2020. Disponible en: https://criterio.hn/maiz-y-catracho-estansiendo-utilizados-para-abrir-los-comercios/

Dong, H. J., Wang, Z. H., Meng, W., Li, C. C., Hu, Y. X., Zhou, L. \& Wang, X. J. (2018). The Natural Compound Homoharringtonine Presents Broad Antiviral Activity In Vitro and In Vivo. Viruses, 10(11), 601. doi: 10.3390/ $\underline{\mathrm{v} 10110601}$

FDA (2020). Letter to Ron H. Lollar. Accesado el 26 de mayo de 2020. Disponible en: https://www.fda.gov/media/137886/ download

Furuta, Y., Komeno, T., \& Nakamura T. (2017). Favipiravir (T705), a broad spectrum inhibitor of viral RNA polymerase. Proceedings of the Japan Academy, Series B, 93(7), 449463. doi: $10.2183 /$ pjab.93.027

Gautret, P., Lagier, J. C., Parola, P., Hoang, V. T., Meddeb, L., Mailhe, M., ... \& Raoult, D. (2020). Hydroxychloroquine and azithromycin as a treatment of COVID-19: Results of an open-label non-randomized clinical trial. International Journal of Antimicrobial Agents, 56, 105949. doi: 10.1016/j. ijantimicag.2020.105949

Geleris, J., Sun, Y., Platt, J., Zucker, J., Baldwin, M., Hripcsak, G., ... \& Schluger, N. W. (2020). Observational Study of Hydroxychloroquine in Hospitalized Patients with Covid-19.The New England Journal of Medicine, 382, 2411-2418. doi: 10.1056/NEJMoa2012410

Ghinai, I., Mcpherson, T. D., Hunter, J. C., Kirking, H. L., Christiansen, D., Joshi, K., ... \& Uyeki, T. M. (2020). First known person-to-person transmission of severe acute respiratory syndrome coronavirus 2 (SARS-CoV-2) in the USA. The Lancet, 395(10230), 1137-1144. doi: 10.1016/ $\underline{\text { S0140-6736(20)30607-3 }}$

Gobierno de Honduras (2020). MAIZ PACK Tratamiento de 10 días. Accesado 15 de agosto de 2020. Disponible en: https:// megalabs.global/wp-content/uploads/2020/06/AnimacionMAIZ-Pack-Gobierno-de-Honduras.pdf

Guan, W. J., Ni, Z. Y., Hu, Y., Liang, W. H., Ou, C. Q., He, J. X., ... \& Li, L. J. (2020). Clinical Characteristics of Coronavirus disease 2019 in China. The New England Journal of Medicine, 382(18), 1708-1720. doi:10.1056/NEJMoa2002032

Grupo de Nanobiosensores y Aplicaciones Bioanalíticas (NanoB2A), Instituto Catalán de Nanociencia y Nanotecnología (ICN2), CSIC, CIBER-BBN y BIST (2020). Técnicas y sistemas de diagnóstico para COVID-19: clasificación, características, ventajas y limitaciones. NanoB2A - ICN2, Diagnóstico COVID-19, Bellaterra, Barcelona, España. Disponible en: https:// www.ciencia.gob.es/stfls/MICINN/Ministerio/FICHEROS/ TecnicasDiagnosticoCOVID19-ICN2.pdf

Hoffman, M., Weber, H. K., Schroeder, S., Krüger, N., Herrler, T., Erichsen, S., ... \& Pöhlmann, S. (2020). SARS-CoV-2 Cell Entry Depends on ACE2 and TMPRSS2 and Is Blocked by Clinically Proven Protease Inhibitor. Cell, 181(2), 271-280. doi: $10.1016 /$ j.cell.2020.02.052

Holshue, M. L., DeBolt, C., Lindquist, S., Lofy, K. H., Wiesman, J., Bruce, H., ... \& Pillai, S. K. (2020). First Case of 2019 Novel Coronavirus in the United States. The New England Journal of Medicine, 382, 929-936. doi: 10.1056/ NEJMoa2001191

Hsu, A., Isaacson, J., Brun, S., Bernstein, B., Lam, W., Bertz, R., ... \& Sun, E. (2003). Pharmacokineticpharmacodynamic analysis of lopinavir-ritonavir in combination with efavirenz and two nucleoside reverse transcriptase inhibitors in extensively pretreated human immunodeficiency virus-infected patients. Antimicrobial Agents and Chemotherapy, 47(1), 350-359. doi: 10.1128/ AAC.47.1.350-359.2003

Jean, S. S., Lee, P. I., \& Hsueh, P. R. (2020). Treatment options 
for COVID-19: The reality and challenges. Journal of Microbiology, Immunology and Infection, 53(3), 436-443. doi.org/10.1016/j.jmii.2020.03.034

Jolles, S., Sewell, W. A. C., C Misbah, S. A. (2005). Clinical uses of intravenous immunoglobulin. Clinical and Experimental Immunology, 142(1), 1-11. doi: 10.1111/j.13652249.2005.02834.x

Jorgensen, S. C., Kebriaei, R., \& Dresser, L. D. (2020). Remdesivir: Review of pharmacology, pre-clinical data and emerging clinical experience for COVID-19. Pharmacotherapy: The Journal of Human Pharmacology and Drug Therapy, 40(7), 659-671. doi: 10.1002/phar.2429

Kadam, R. U. \& Wilson, I. A. (2016). Structural basis of influenza virus fusion inhibition by the antiviral drug Arbidol. Proceedings of the National Academy of Sciences of the United States of America, 114(2), 206-214. doi: 10.1073/ pnas. 1617020114

Kampf, G., Todt, D., Pfaender, S., \& Steinmann, E. (2020). Persistence of coronaviruses on inanimate surfaces and their inactivation with biocidal agents. Journal of Hospital Infection, 104(3), 246-251. doi: 10.1016/j.jhin.2020.01.022 Kamps, B. S. \& Hoffmann, C. (2020). COVID Reference. Steinhäuser Verlag, Alemania. Accesado 12 de junio de 2020. Disponible en: https://covidreference.com

Khan, A., Benthin, C., Zeno, B., Albertson, T. E., Boyd, J., Christie, J. D., ... \& Lazaar, A. L. (2017). A pilot clinical trial of recombinant human angiotensin-converting enzyme 2 in acute respiratory distress syndrome. Critical Care, 21, 234. doi: $10.1186 / \mathrm{s} 13054-017-1823-\mathrm{X}$

Ksiazek, T. G, Erdman, D., Goldsmith, C. S., Zaki, S. R., Peret, T., Emery, S. ... \& Anderson, L. J. (2003). A Novel Coronavirus Associated with Severe Acute Respiratory Syndrome. The New England Journal of Medicine, 348, 1953-1966. doi: 10.1056/NEJMoa030781

Kuba, K., Imai, Y., Ohto-Nakanishi, T., \& Penninger, J. M. (2010) Trilogy of ACE2: A peptidase in the renin-angiotensin system, a SARS receptor, and a partner for amino acid transporters. Pharmacology \& Therapeutics, 128(1), 119128. doi: $10.1016 /$ j.pharmthera.2010.06.003
Laboratorio Centro de Diagnóstico Clínico (2020). Interpretación de los resultados de las pruebas moleculares y serológicas para COVID-19.

Lai, C. C., Shih, T. P., Ko W. C., Tang, H. J., \& Hsueh, P. R. (2020). Severe acute respiratory syndrome coronavirus 2 (SARS-CoV-2) and corona virus disease-2019 (COVID-19): the epidemic and the challenges. International Journal of Antimicrobial Agents, 55(3), 105924. doi: 10.1016/j. ijantimicag.2020.105924

Lauer, S. A., Grantz, K. H., Bi, Q., Jones, F. K., Zheng, Q., Meredith, H. R., ... \& Lessler, J. (2020). The incubation period of coronavirus disease 2019 (COVID-19) from publicly reported confirmed cases: estimation and application. Annals of Internal Medicine, 172(9), 577-582. doi: 10.7326/M20-0504

Leung, W.K., To, K. F., Chan, P. K. S., Chan, H. L. Y., Wu, A. K. L., Lee, N., ... \& Sung, J. J. Y. (2003). Enteric Involvement of Severe Acute Respiratory Syndrome-Associated Coronavirus Infection. Gastroenterology, 125(4), 10111017. doi: $10.1016 /$ j.gastro.2003.08.001

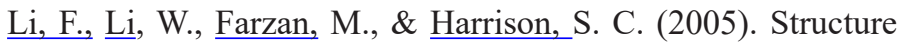
of SARS Coronavirus Spike Receptor-Binding Domain Complexed With Receptor. Science, 309(5742), 1864-1868. doi: $\underline{10.1126 / \text { science. } 1116480}$

Li, Z., Yi, Y., Luo, X., Xiong, N., Liu, Y., Li, S., ... \& Ye, F. (2020). Development and clinical application of a rapid IgM-IgG combined antibody test for SARS-CoV-2 infection diagnosis. Journal of Medical Virology, 92(9), 1518-1524. doi: $\underline{10.1002 / j m v .25727}$

Luo, P., Liu, Y., Qiu, L., Liu, X., Liu, D., \& Li, J. (2020). Tocilizumab treatment in COVID-19: A single center experience. Journal of Medical Virology, (92)7, 814-818. doi: 10.1002/jmv.25801

Medina, M. T., \& Moncada, S. S. (2020). Hydroxychloroquine/ chloroquine as a treatment choice or prophylaxis for Covid-19 at the primary care level in developing countries: A Primum non Nocere dilemma. Journal of Neurological Sciences, 415, 116972. doi: 10.1016/j.jns.2020.116972

Microdacyn (2020) Microdacyn. Accesado el 18 de agosto de 
2020. Disponible en: https://microdacyn.com.mx/

Mulangu, S., Dodd, L. E., Davey Jr, R. T., Tshiani Mbaya, O., Proschan, M., Mukadi, D., ... Muyembe-Tamfum, J. J. (2019). A randomized, controlled trial of Ebola virusdisease therapeutics. The New England Journal of Medicine, 381(24), 2293-2303. doi: 10.1056/NEJMoa1910993

OMS (2020a). Coronavirus causante del síndrome respiratorio de Oriente Medio (MERS-CoV). Accesado 19 de mayo de 2020. Disponible en: https://www.who.int/es/newsroom/fact-sheets/detail/middle-east-respiratory-syndromecoronavirus-(mers-cov)

OMS (2020b). Laboratory testing for 2019 novel coronavirus (2019-nCoV) in suspected human cases. Interim guidance 19 March 2020. Disponible en: https://www.who.int/ publications/i/item/laboratory-testing-for-2019-novelcoronavirus-in-suspected-human-cases-20200117

OMS (2020c). Ensayo clínico "Solidaridad" sobre tratamientos contra la COVID-19. Accesado 1 de agosto de 2020. Disponible en: https://www.who.int/es/emergencies/ diseases/novel-coronavirus-2019/global-research-on-novelcoronavirus-2019-ncov/solidarity-clinical-trial-for-covid19-treatments

OPS/OMS (2020). Directrices provisionales de bioseguridad de laboratorio para el manejo y transporte de muestras asociadas al nuevo coronavirus 2019 (2019-nCoV). Disponible en: https://iris.paho.org/handle/10665.2/51896

Padhye, N. S. (2020). Reconstructed diagnostic sensitivity and specificity of the RT-PCR test for COVID-19. medRxiv. doi: $\underline{10.1101 / 2020.04 .24 .20078949}$

Secretaria de Salud de Honduras. (2020a). Lineamientos para el manejo clínico ambulatorio de pacientes con COVID-19 según estadíos de la enfermedad. Disponible en: http://www. desastres.hn/COVID-19/SESAL-Atencion-Ambulatoria. COVID-19.pdf

Secretaria de Salud de Honduras (2020b). Protocolo de manejo clínico de pacientes adultos con covid-19 según estadíos de la enfermedad en los distintos niveles de atención (primera versión). Disponible en: https://covid19honduras. org/?q=protocolos
Secretaria de Salud de Honduras (2020c). Protocolo de manejo clínico de pacientes adultos con covid-19 según estadíos de la enfermedad en los distintos niveles de atención (segunda versión). Disponible en: http://www.salud.gob.hn/site/ index.php/component/edocman/protocolo-de-manejoclinico-del-paciente-adulto-con-covid-19-segun-las-etapasde-la-enfermedad-en-las-redes-de-servicio-de-salud

Sheahan, T. P., Sims, A. C., Leist, S. R., Schäfer, A., Won, J., Brown, A. J., .. \& Baric, R. S. (2020). Comparative therapeutic efficacy of remdesivir and combination lopinavir, ritonavir, andinterferon beta against MERS-CoV. Nature Communications, 11, 1-14. doi: 10.1038/s41467019-13940-6

Shereen, M. A., Khan, S., Kazmi, A., Bashir, N., \& Siddique, R. (2020). COVID-19 infection: origin, transmission, and characteristics of human coronaviruses. Journal of Advanced Research, 24, 91-98. doi: 10.1016/j.jare.2020.03.005

Shi, Z., \& Hu, Z. (2008). A review of studies on animal reservoirs of the SARS coronavirus. Virus Research, 133(1), 74-87. doi: 10.1016/j.virusres.2007.03.012

Skalny, A. V., Rink, L., Ajsuvakova, O. P., Aschner, M., Gritsenko, V. A., Alekseenko, S. I., ... \& Tinkov, A. A. (2020). Zinc and respiratory tract infections: Perspectives for COVID-19 (Review). International Journal of Molecular Medicine, 46(1), 17-26. doi: 10.3892/ijmm.2020.4575

Thachil, J. (2020). The versatile heparin in COVID-19. Journal of Thrombosis and Haemostasis, 18(5), 1020-1022. doi: $\underline{10.1111 / \mathrm{jth} .14821}$

Tang, W., Cao, Z., Han, M., Wang, Z., Chen, J., Sun, W., ... \& Xie, Q. (2020). Hydroxychloroquine in patients with mainly mild to moderate coronavirus disease 2019: open label, randomised controlled trial. $B M J, 369$, m1849. doi: 10.1136/bmj.m1849

Tsioris, K., Gupta, N. T., Ogunniyi, A. O., Zimnisky, R. M. Qian, F., Yao, Y., ... \& Love, C. (2015). Neutralizing antibodies against West Nile virus identified directly from human B cells by single-cell analysis and next generation sequencing. Integrative Biology, 7(12), 1587-1597. doi: 10.1039/ $\underline{\mathrm{c} 5 \mathrm{ib} 00169 \mathrm{~b}}$ 
Tu, Y. F., Chien, C. S., Yarmishyn, A. A., Lin, Y. Y., Luo, Y. H., Lin, Y., ... \& Chiou, S. H. (2020). A review of SARS$\mathrm{CoV}-2$ and the ongoing clinical trials. International Journal of Molecular Sciences, 21(7), 2657. doi: 10.3390/ ijms21072657

van Doremalen, Morris, D. H., Holbrook, M. G., Gamble, A., Williamson, B. N., Tamin, A., ... \& de Wit, E. (2020). Aerosol and surface stability of SARS-CoV-2 as compared with SARS-CoV-1. The New England Journal of Medicine, 382, 1564-1567. doi: 10.1056/NEJMc2004973

Vargesson, N. (2015). Thalidomide-induced teratogenesis: History and mechanisms. Birth Defects Research Part C: Embryo Today: Reviews, 105(2), 140-156. doi: 10.1002/ $\underline{\text { bdrc. } 21096}$

Vincent, M. J., Bergeron, E., Benjannet, S., Erickson, B. R., Rollin, P. E., Ksiazek, T. G., ... \& Nichol, S. T. (2005). Chloroquine is a potent inhibitor of SARS coronavirus infection and spread. Virology Journal, 2, 69. doi: $\underline{10.1186 / 1743-422 X-2-69}$

Voiriot, G., Razazi, K., Amsellem, V., Van Nhieu, J. T., Abid, S., Adnot, S., ... \& Maitre, B. (2017). Interleukin-6 displays lung anti-inflammatory properties and exerts protective hemodynamic effects in a double-hit murine acute lung injury. Respiratory Research, 18, 64. doi: 10.1186/s12931$\underline{017-0553-6}$

Wagstaff, K. M., Sivakumaran, H., Heaton, S. M., Harrich, D., \& Jans, D. A. (2012). Ivermectin is a specific inhibitor of importin alpha/beta-mediated nuclear import able to inhibit replication of HIV-1 and dengue virus. Biochemical Journal, 443(3), 851-856. doi: 10.1042/BJ20120150

Wan, Z., Zhang, Y. N., He, Z., Liu, J., Lan, K., Hu, Y., \& Zhang, C. (2016). A melting curve-based multiplex RTqPCR assay for simultaneous detection of four human coronaviruses. International Journal of Molecular Sciences, 17(11), 1880. doi 10.3390/ijms17111880

Wang, Y., Jiang, W., He Q., Wang, C., Wang, B., Zhou, P., .. \& Tong, Q. (2020a). A retrospective cohort study of methylprednisolone therapy in severe patients with COVID-19 pneumonia. Signal Transduction and Targeted
Therapy, 5, 57. doi: 10.1038/s41392-020-0158-2

Wang, M., Cao, R., Zhang, L., Yang, X., Liu, J., Xu, M., ... \& Xiao, G. (2020b). Remdesivir and chloroquine effectively inhibit the recently emerged novel coronavirus (2019$\mathrm{nCoV})$ in vitro. Cell Research, 30, 269-271. doi: $\underline{10.1038 /}$ s41422-020-0282-0

Wise, J. (2020). Covid-19: Study reveals six clusters of symptoms that could be used as a clinical prediction tool. $B M J, 370$, m2911. doi: 10.1136/bmj.m2911

Zhang, J., Ma, X., Yu, F., Liu, J., Zou, F., Pan, T., \& Zhang, H. (2020a). Teicoplanin potently blocks the cell entry of 2019nCoV. bioRxiv. doi:10.1101/2020.02.05.935387

Zhang, W., Zhao, Y., Zhang, F., Wang, Q., Li, T., Liu, Z., ... \& Zhang, S. (2020b). The use of anti-inflammatory drugs in the treatment of people with severe coronavirus disease 2019 (COVID-19): The Perspectives of clinical immunologists from China. Clinical Immunology, 214,108393. doi: 10.1016/j.clim.2020.108393

Zhong N. S., Zheng, B. J., Li, Y. M., Poon, L. L. M., Xie, Z. H., Chan, K. H., \& Guan, D. Y. (2003). Epidemiology and cause of severe acute respiratory syndrome (SARS) in Guangdong, People's Republic of China, in February, 2003. The Lancet, 362(9393), 1353-1358. doi: 10.1016/s0140$\underline{6736(03) 14630-2}$ 